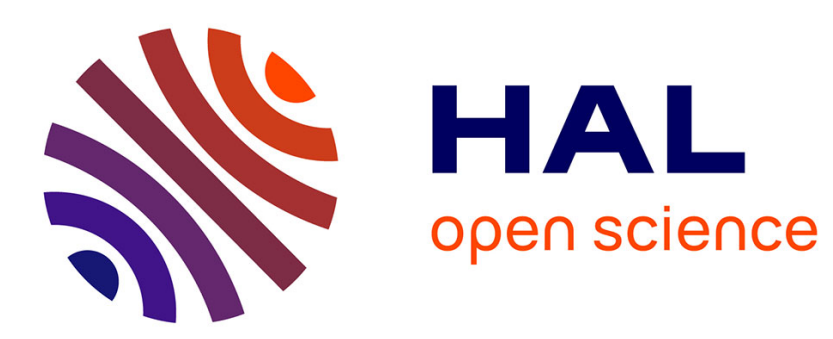

\title{
EL2 distribution in LEC GaAs ingots and wafers
}

M. Bonnet, N. Visentin, B. Goutéraux

\section{To cite this version:}

M. Bonnet, N. Visentin, B. Goutéraux. EL2 distribution in LEC GaAs ingots and wafers. Revue de Physique Appliquée, 1988, 23 (5), pp.739-746. 10.1051/rphysap:01988002305073900 . jpa-00245879

\section{HAL Id: jpa-00245879 https://hal.science/jpa-00245879}

Submitted on 1 Jan 1988

HAL is a multi-disciplinary open access archive for the deposit and dissemination of scientific research documents, whether they are published or not. The documents may come from teaching and research institutions in France or abroad, or from public or private research centers.
L'archive ouverte pluridisciplinaire HAL, est destinée au dépôt et à la diffusion de documents scientifiques de niveau recherche, publiés ou non, émanant des établissements d'enseignement et de recherche français ou étrangers, des laboratoires publics ou privés. 
Classification

Physics Abstracts

$61.70-72.80 \mathrm{E}-78.50 \mathrm{G}$

\title{
EL2 distribution in LEC GaAs ingots and wafers
}

\author{
M. Bonnet, N. Visentin and B. Gouteraux \\ THOMSON-CSF/T.H.M., Route Départementale 128, B.P. 48, 91401 Orsay Cedex, France
}

(Reçu le 28 septembre 1987, accepté le 18 février 1988)

\begin{abstract}
Résumé. - La distribution du défaut EL2 dans des plaquettes de GaAs semi-isolant a été mesurée par des techniques électriques et optiques. Nous avons également suivi l'influence des conditions de croissance telles que la stoechiométrie, la fraction solidifiée et l'humidité de l'encapsulant sur la distribution de EL2 et des impuretés résiduelles.
\end{abstract}

\begin{abstract}
A combination of electrical and optical mapping experiments has been used to obtain the EL2 distribution patterns in semi-insulating $\mathrm{GaAs}$ wafers. The influence of growing conditions such as stoichiometry, mass fraction solidified and moisture in the encapsulant is shown in terms of EL2 uniformity and residual doping level.
\end{abstract}

\section{Introduction.}

The so-called EL2 center is known to be responsible for the semi-insulating properties of undoped $\mathrm{GaAs}$ crystals grown by the Liquid Encapsulation Czochralski (LEC) method. This material is mainly used for making microwave and digital integrated circuits based on MESFET devices with the active layer being achieved by direct ion implantation. The short and long-range uniformity of the device properties over a two or three-inch diameter wafer is of prime importance for the circuits to operate and for the fabrication yield.

A lot of different experiments have been carried on to measure the long range distribution of electrical properties [1-6] and the homogeneity of FET parameters [7-12] on the wafers. The resulting maps often show a close correlation between the distributions of the parameters and of the dislocations. This correlation is also valid for microscopic variations (short-range uniformity).

The local variation of electrical activation of the implanted ions must be responsible for this distribution of properties in active layers. The activation of the implanted ions is closely related to the local equilibrium between shallow and deep levels in the semi-insulating substrate. In order to have a better understanding of this effect, we have analysed the distribution of EL2 center in the undoped semiinsulating ingots, grown in our laboratory, by using a combination of Hall effect and optical absorption measurements on a two-inch wafer [13]. The distribution of EL2 has also been measured with optical [18-20], or electrical experiments [21].

\section{Crystal growth.}

The crystals were grown with the LEC method. The in-situ synthesis with high-pressured argon is achieved in a pyrolytic boron nitride crucible to avoid any silicon contamination. The stoichiometry of liquid $\mathrm{GaAs}$ was controlled to get a semi-insulating material with a $\mathrm{Ga}$ to As ratio inferior or equal to 1 [14]. The initial liquid charge is about $3 \mathrm{~kg}$ and the ingots were grown with a 60 to $65 \mathrm{~mm}$ diameter and then grinded down to $50 \mathrm{~mm}$.

\section{The determination of EL2 concentration.}

We have assumed a simple three-energy-level model $E_{\mathrm{A}}, E_{\mathrm{D}}$ and EL2 where the electrical neutrality equation can be expressed as :

$$
n+N_{\mathrm{A}}^{-}=p+N_{\mathrm{D}}^{+}+\left[\mathrm{EL} 2^{+}\right]
$$

with $N_{\mathrm{A}}\left(N_{\mathrm{D}}\right)$ as the concentrations of acceptors (donors) and $n(p)$ as the concentration of free electrons (holes) in the conduction (valence) band.

In semi-insulating $\mathrm{GaAs}$ we have mixed conduction of electrons and holes. The resolution of the equation (1) gives the position of the Fermi level, $E_{\mathrm{F}}$, in the gap. A Shockley diagram (Fig. 1) is an elegant graphical method to solve this equation in 


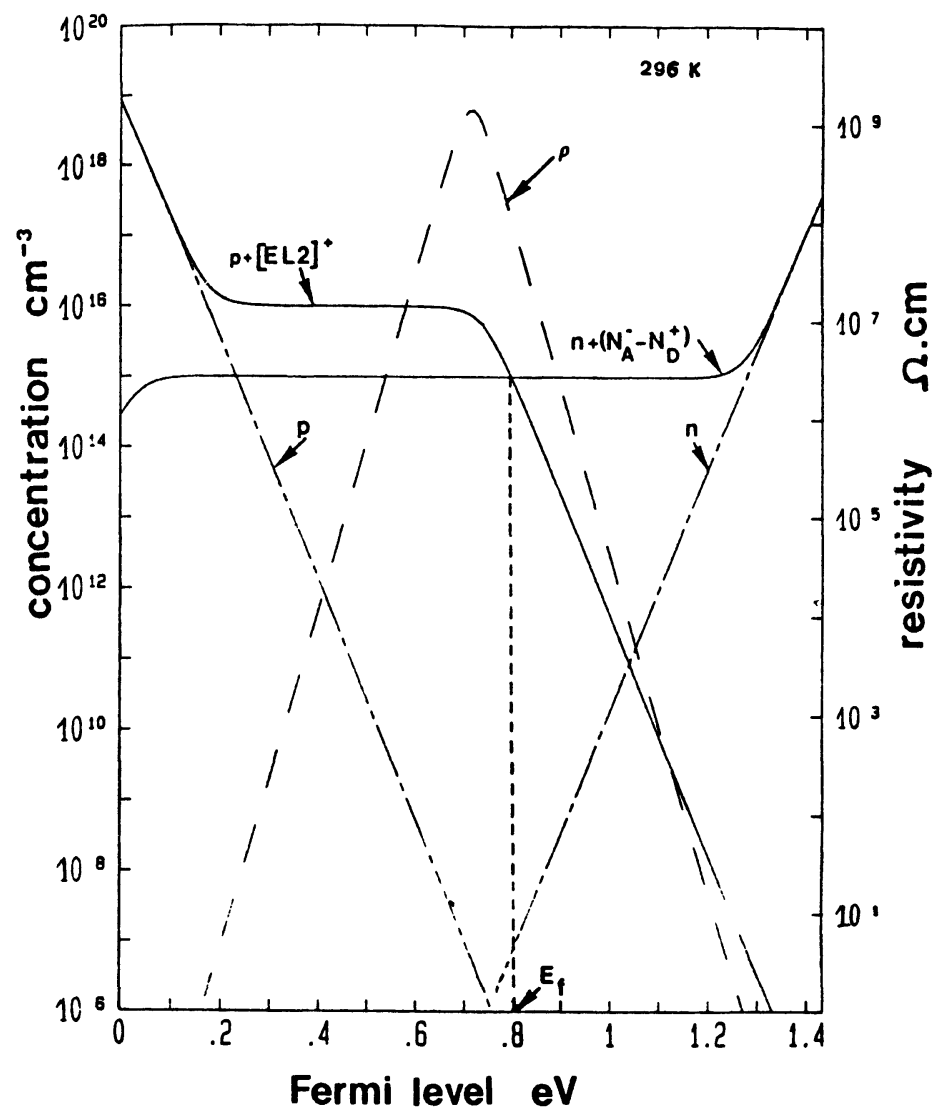

Fig. 1. Shockley diagram at $296 \mathrm{~K}$ for $[\mathrm{EL} 2] /\left(N_{\mathrm{A}}-N_{\mathrm{D}}\right)=10$ and $[\mathrm{EL} 2]=10^{16} \mathrm{~cm}^{-3}$.

terms of compensation ratio [EL2]/ $\left(N_{\mathrm{A}}-N_{\mathrm{D}}\right)$. With the corresponding computation of resistivity and mobility, figure 1 shows that GaAs is $N$-type and semi-insulating $\left(\rho>10^{7} \Omega . \mathrm{cm}\right.$ at $\left.296 \mathrm{~K}\right)$ if the compensation ratio ranges from 1 to $100[15,16]$. In this case, the neutrality equation can be reduced to :

$$
N_{\overline{\mathrm{A}}}^{-}-N_{\mathrm{D}}^{+}=\left[\mathrm{EL}^{+}\right] \text {. }
$$

The following expression for $n$ can be deduced :

$n(T)=\left[\frac{[\mathrm{EL} 2]}{\left(N_{\mathrm{A}}-N_{\mathrm{D}}\right)}-1\right] N_{\mathrm{C}}(T) \exp \left[\frac{-E_{n}^{\prime}(T)}{k T}\right]$

where $E_{n}^{\prime}(T)=\left(0.759-2.37 \times 10^{-4} . T\right) \mathrm{eV}$ is the total ionization energy of EL2 [17] and $N_{\mathrm{C}}(T)$ is the effective density of states in the conduction band.

We can notice that, for a compensation ratio inferior to 1 , the material is $P$-type and conducting, owing to the absence of any deep acceptor level.

The characterization of bulk semi-insulating GaAs involves three important parameters : resistivity $\rho$, Hall mobility $\mu_{H}$ and EL2 concentration [EL2]. We can measure their distribution on wafers by combining mappings of Hall effect at $400 \mathrm{~K}$ and optical absorption at $296 \mathrm{~K}[13,16]$.

To compute the occupation rate of the EL2 center at $296 \mathrm{~K}$, we need the activation energy $\left(E_{\mathrm{A}}\right)$ of the
Hall constant $\left(R_{\mathrm{H}}\right)$. For undoped semi-insulating $\mathrm{GaAs}, E_{\mathrm{A}}$ is close to $0.76 \mathrm{eV}$ and the small deviations from the theoretical value of $0.759 \mathrm{eV}$ can be accounted for by the existence of a family of deep levels $[22,23]$

From now on we will assume a unique level associated with the EL2 family. When the experimental value of $E_{\mathrm{A}}$, deduced from $R_{\mathrm{H}}(T)$ measurement, is close to $0.76 \mathrm{eV}$, we can state that EL2 is responsible for the compensation and we deduce from equation (2) that :

$$
n(T)=1 / q R_{\mathrm{H}}(T) .
$$

The optical absorption coefficient of the EL2 centre is the sum of the capture rate of electrons from the valence band and the emission rate of electrons to the conduction band at wavelength $\lambda$ :

$$
\alpha(\lambda)=\sigma_{\mathrm{n}}^{0}(\lambda) N_{\mathrm{EL} 2}^{0}+\sigma_{\mathrm{p}}^{0}(\lambda) N_{\mathrm{EL} 2}^{+}
$$

$\sigma_{\mathrm{n}}^{0}(\lambda)\left(\sigma_{\mathrm{p}}^{0}(\lambda)\right)$ is the photo-ionization cross-section of the centre for electrons (holes).

The total concentration of EL2 is then :

$$
\begin{aligned}
& {[\mathrm{EL} 2]=\frac{\alpha(\lambda)}{f_{\mathrm{EL} 2}} } \cdot \frac{1}{\sigma_{\mathrm{n}}^{0}(\lambda)} \times \\
& \times\left[1+\frac{\sigma_{\mathrm{p}}^{0}(\lambda)}{\sigma_{\mathrm{n}}^{0}(\lambda)} \cdot\left(\frac{1}{f_{\mathrm{EL} 2}}-1\right)\right]^{-1}
\end{aligned}
$$


where

$$
f_{\mathrm{EL} 2}=\left[1+\frac{N_{\mathrm{C}}(T)}{n(T)} \exp \left(-\frac{E_{n}^{\prime}(T)}{k T}\right)\right]^{-1}
$$

is the occupation rate of EL2.

If $n\left(T^{\prime}\right)=1 / q \cdot R_{\mathrm{H}}(T)$ and if we select a wavelength $\lambda_{0}$ which gives $\sigma_{\mathrm{p}}^{0}\left(\lambda_{0}\right) / \sigma_{\mathrm{n}}^{0}\left(\lambda_{0}\right) \ll 1$, the equation (3) is reduced to a very simple expression :

$$
[\mathrm{EL} 2]=\frac{\alpha\left(\lambda_{0}\right)}{f_{\mathrm{EL} 2}} \frac{1}{\sigma_{\mathrm{n}}^{0}\left(\lambda_{0}\right)} .
$$

This is the case for $\lambda_{0}=1.10 \mu \mathrm{m}$ or $E_{0}=1.13 \mathrm{eV}$ [24] and $f_{\mathrm{EL} 2}$ is obtained easily by measuring $R_{\mathrm{H}}(T)$. So, we can compute the value of $N_{\mathrm{A}}-$ $N_{\mathrm{D}}$ by using equation (2) in order to obtain the distribution of the residual shallow impurity level.

\section{Experimental.}

4.1 HALl EFFECT MAPPING. - An automatic Hall effect mapping experiment has been set up $[6,25]$ in order to measure resistivity and Hall constant of more than 800 square samples on a two-inch wafer with a spatial resolution of $1.5 \times 1.5 \mathrm{~mm}^{2}$. The rows of $700 \mu \mathrm{m}$ diameter $\mathrm{Au}-\mathrm{Ge}$ contacts are previously evaporated through a metal mask on the total area of the wafer.

After a four-minutes annealing at $420^{\circ} \mathrm{C}$ under a $\mathrm{N}_{2}$ flow, to obtain good ohmic contacts, the wafer is stuck on to a glass substrate with an insulating adhesive layer. Then the four-contact samples are separated from each other by sawing through the circular contacts (Fig. 2).

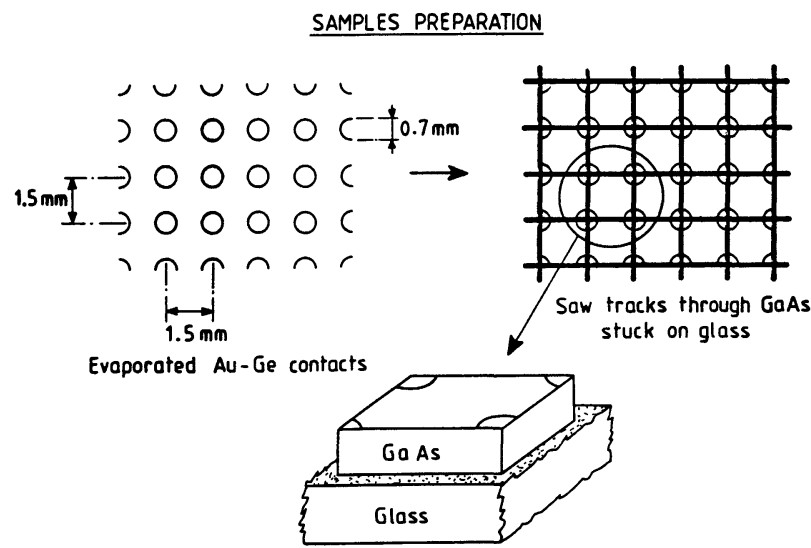

Fig. 2. - Hall effect wafers preparation.

The measurements can be performed in the temperature range 300 to $500 \mathrm{~K}$ by using a non-magnetic heating plate with the wafer vacuum locked to it. $\mathrm{X}$ - Y stepping motors drive all this equipment with a $10 \mu \mathrm{m}$ accuracy. A four-point probe, capable of a $Z$-motion, and adjustable contact pressure permit electrical measurements. All the movements, the alignment and the scanning sequence are monitored by a 6800 microprocessor connected through a IEEE 488 bus interface to a microcomputer. The current source, the electrometer, the scanner selecting the appropriate current-voltage configuration and the electromagnet supplying the magnetic field (Fig. 3) are connected on the same bus.

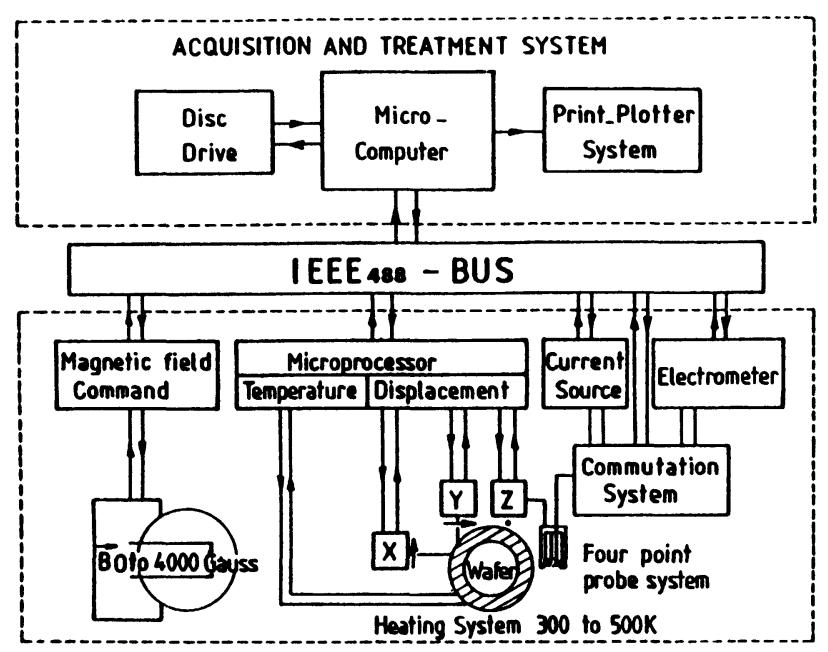

Fig. 3. - Schematic of the automatic Hall effect distribution experiment.

The validity of each measurement is checked in terms of contact ohmicity and size factor. Thermomagnetic and thermo-electric parasitic effects are suppressed by measuring the electrical current and magnetic field in direct and reverse conditions. Three scanning sequences are required.

When the scannings are completed a subroutine gives the histogram of each parameter and computes the average values and the standard deviations. The final step involves an interactive allocation of coding and the subsequent plotting of the map.

The measurements on semi-insulating GaAs are generally made at $400 \mathrm{~K}$ in order to decrease the time constant of each measurement and to have enough current for stability.

4.2 OPTICAL ABSORPTION MAPPING. - We will assume that the losses through the wafer are only due to absorption and reflection mechanisms in a continuous medium. This assumption is valid in our experiment because we measure the average transmitted light intensity over a large area $(1.5 \times$ $1.5 \mathrm{~mm}^{2}$ ) compared with the microscopic size of diffusion centres observed around dislocations on transmission images [26].

The transmission (intensity ratio) is given by :

$$
T=\frac{(1-R)^{2} \exp (-\alpha W)}{1-R^{2} \exp (-\alpha W)}
$$


where $R$ is the reflection coefficient $(0.295$ for GaAs), $\alpha$ is the absorption coefficient and $W$ is the thickness of the wafer.

Then :

$$
\alpha=\frac{1}{W} \operatorname{Ln}\left[\frac{(1-R)^{2}+\left[(1-R)^{4}+4 T^{2} R^{2}\right]^{1 / 2}}{2 T}\right]
$$

and the theoretical maximum transmission for $\alpha>0$ is :

$$
T_{\mathrm{M}}=\frac{(1-R)^{2}}{1-R^{2}}=54.14 \% \text {. }
$$

We can notice that, if we want to keep a good resolution, $W$ must be $\geqslant 3 \mathrm{~mm}$ because $\alpha$ is of the order of $1 \mathrm{~cm}^{-1}$, and the wafer must be double-side polished in order to avoid diffusion by the surface roughness.

The light source is a tungsten-halogen lamp and the wavelength can be changed or selected by a diffraction grating monochromator. The wavelengths smaller than $0.7 \mu \mathrm{m}$ are eliminated by a high-pass filter and the incident light intensity is modulated at $1 \mathrm{kHz}$. The light beam has a square-shaped crosssection of $1.5 \times 1.5 \mathrm{~mm}^{2}$ and the transmitted light is detected by a $\mathrm{PbS}$ photo-detector. Then the signal is measured with a lock-in amplifier (Fig. 4). The wavelength has been fixed at $1.10 \mu \mathrm{m}(1.13 \mathrm{eV})$ to avoid the absorption tails that can be neglected any longer when we are close to the band gap absorption. We have also checked that the absorption at $1.13 \mathrm{eV}$ is due only to EL2 by quenching this level at $4 \mathrm{~K}$ with a YAG laser.

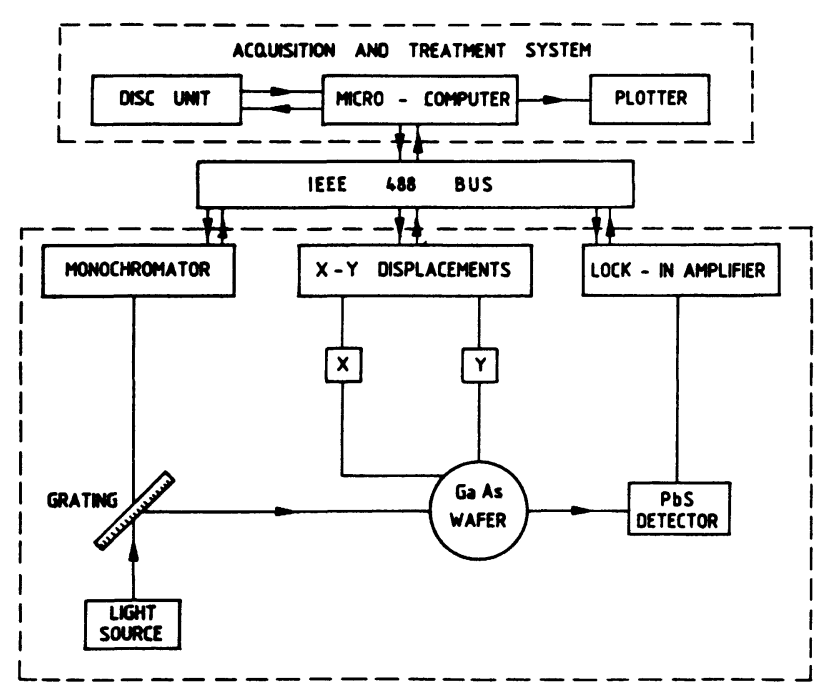

Fig. 4. - Schematic of the optical absorption mapping experiment.

The wafer is moved perpendicularly to the light beam by stepping motors. The monochromator, the lock-in amplifier and the stepping motors are connected to a IEEE bus. A microcomputer controls all the displacements of the wafer and the measurements. It is then possible to draw a distribution histogram of the absorption coefficient and the corresponding map.

$\alpha(\lambda)$ can be obtained with a $2 \%$ accuracy.

\section{Results.}

Two wafers have to be measured for Hall effect and optical absorption.

\subsection{INFLUENCE OF MASS FRACTION SOLIDIFIED ON} RADIAL UNIFORMITY. - The axial position of a wafer in an ingot is always given in terms of mass fraction solidified $M_{\mathrm{f}}$, which is the ratio of the solid GaAs mass to the initial liquid GaAs mass.

The lowest values of $M_{\mathrm{f}}$ correspond to the seedend part of the ingot.

\subsubsection{Resistivity. Hall constant and free carriers. -} All the ingots are $N$-type and semi-insulating with a free carrier concentration proportionnal to the inverse of the Hall constant. The $R_{\mathrm{H}}$ maps always present the same distribution patterns as the resistivity maps but with less precise contours.

These small local deviations are due to experimental complexity : The $R_{\mathrm{H}}$ determination requires three scannings of the wafer, which can increase the experimental errors:

At $400 \mathrm{~K}$, the resistivity distribution observed in the upper part of the ingots $\left(M_{\mathrm{f}}<60 \%\right)$ always presents four maxima located approximately in the middle of the wafer radii along the $\langle 110\rangle$ directions (Fig. 5). This pattern is found until $M_{\mathrm{f}}$ reaches a threshold value $(\simeq 60 \%)$ which depends on the conditions of growth. Beyond this value, the symmetry slowly changes towards a pseudo-revolution symmetry with the presence of a lower resistivity core (Fig. 6) which can sometimes be slightly shifted from the ingot centre.

The Hall constant maps give the same distribution and the $R_{\mathrm{H}}$ maxima (free carrier concentration minima) correspond to the resistivity maxima on the wafers.

5.1.2 Optical absorption. - The optical absorption coefficient measured at $296 \mathrm{~K}$ is distributed along a four-fold symmetry for wafers coming from the upper part of the ingots $\left(M_{\mathrm{f}}<60 \%\right)$ (Fig. 7) with minima located along the $\langle 110\rangle$ axis of the crystal. When $M_{\mathrm{f}}$ increases, the distribution pattern evolves towards a symmetry loss different from the one observed for electrical parameters (Fig. 8).

We obtain very similar maps for both absorption coefficient and EL2 concentration (Fig. 9). 


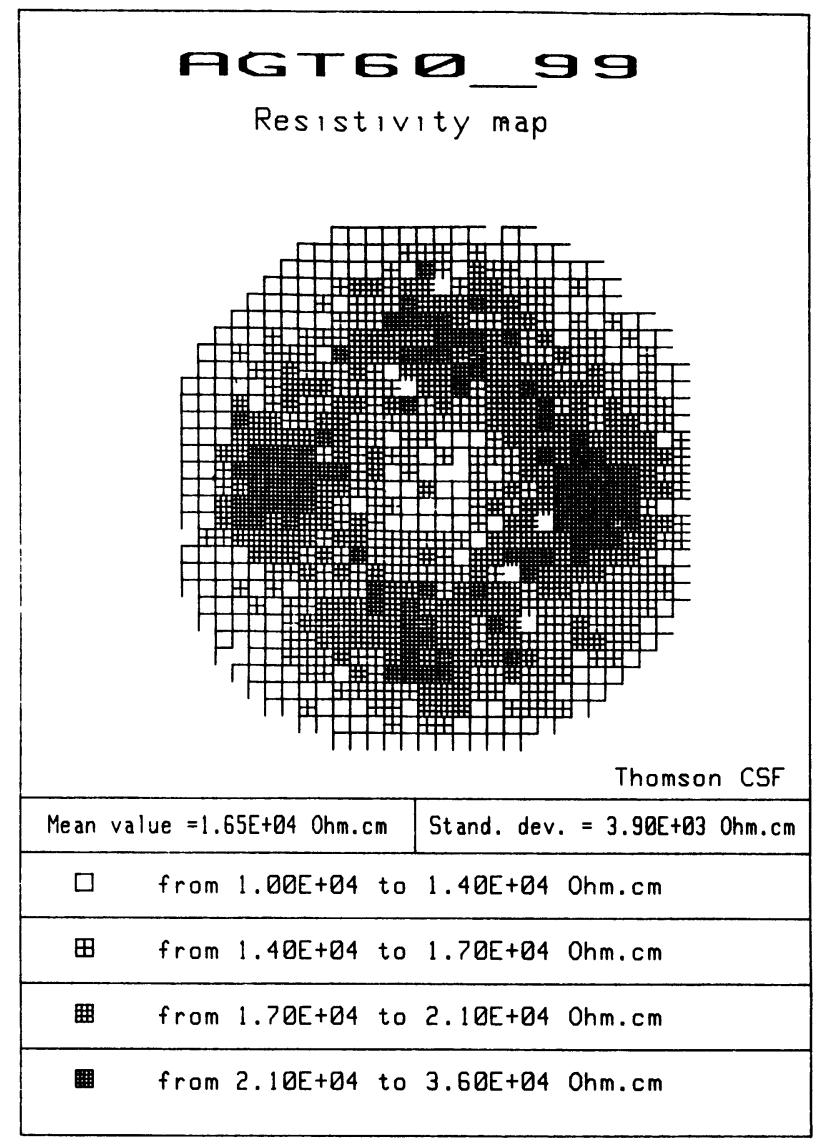

Fig. 5. - Resistivity map at $400 \mathrm{~K}$ for a typical seed-end wafer.

By computing the residual doping level distribution we can see that $N_{\mathrm{A}}-N_{\mathrm{D}}$ maps fit resistivity or Hall constant maps (Fig. 10) best for $M_{\mathrm{f}}>$ $60 \%$.

As a conclusion, the distribution patterns of resistivity (or Hall constant) and EL2 concentration are similar for $M_{\mathrm{f}}<60 \%$ but near the tail end of the ingots $\left(M_{\mathrm{f}}>60 \%\right)$ the best fit is obtained between electrical parameters and residual doping level.

5.2 AXIAl Distribution. - The axial distribution of the average value of EL2 concentration depends on the stoichiometry variation during the growth. When the growth starts from an As-rich (Ga-rich) melt, the $\mathrm{As}(\mathrm{Ga})$ concentration increases in the melt with $M_{\mathrm{f}}$ and the EL2 concentration increases (decreases) in the solid. The problem is to measure accurately the deviation of the melt from stoichiometry. We are only able to observe large deviations by measuring the mass balance before and after GaAs synthesis and only for As-loss.

\section{Discussion.}

6.1 EL2 CONCENTRATION. - The EL2 concentration measured in the undoped semi-insulating

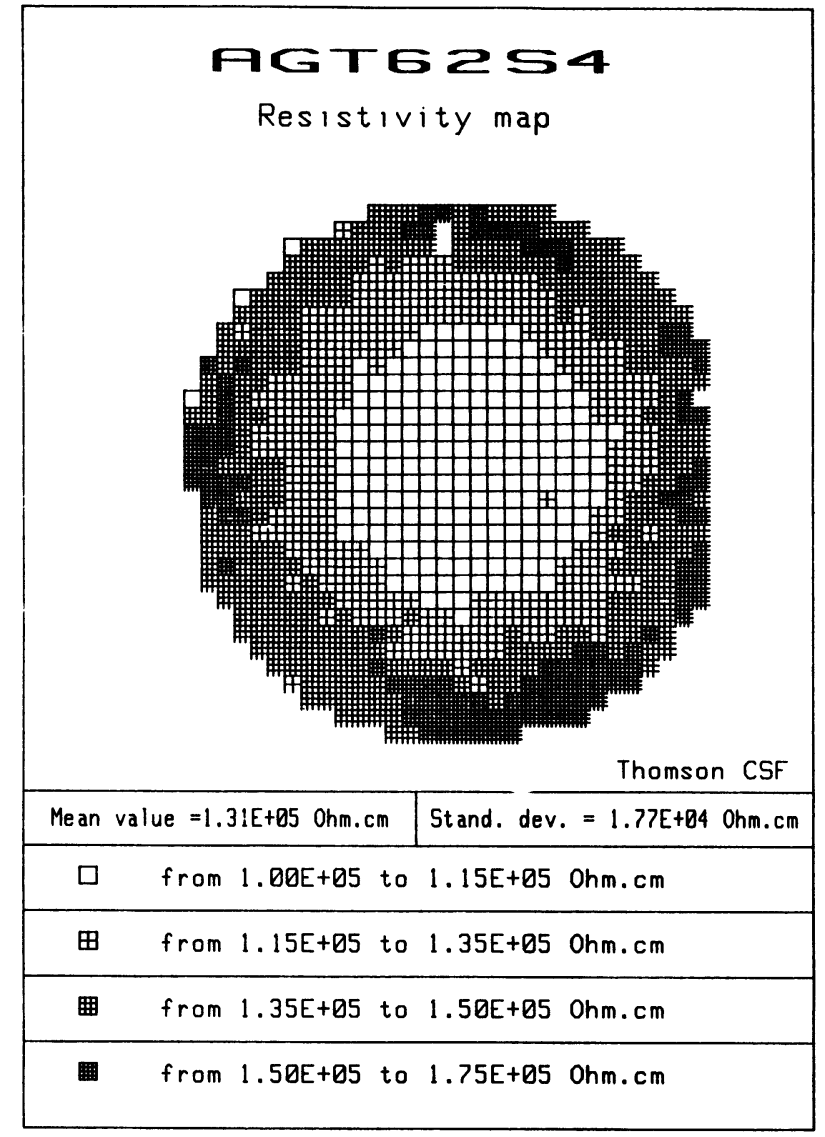

Fig. 6. - Resistivity map at $400 \mathrm{~K}$ for a typical tail-end wafer.

material is of the order of $2 \times 10^{16} \mathrm{~cm}^{-3}$ with an average relative standard deviation ranging from $5 \%$ to $20 \%$ depending on the conditions of growth.

The residual doping level $\left(N_{\mathrm{A}}-N_{\mathrm{D}}\right)$ is around $3 \times 10^{15} \mathrm{~cm}^{-3}$ with a relative standard deviation ranging from $10 \%$ to $20 \%$.

Nevertheless, both concentration values depend on the moisture of the $\mathrm{B}_{2} \mathrm{O}_{3}$ encapsulant. For a dry encapsulant $\left(150 \mathrm{ppm} \mathrm{H}_{2} \mathrm{O}\right)$ EL2 concentration is more than $2 \times 10^{16} \mathrm{~cm}^{-3}$ and $N_{\mathrm{A}}-N_{\mathrm{D}}$ is more than $2 \times 10^{15} \mathrm{~cm}^{-3}$. For a wet $\mathrm{B}_{2} \mathrm{O}_{3}\left(300 \mathrm{ppm} \mathrm{H} \mathrm{H}_{2} \mathrm{O}\right)$ EL2 concentration is less than $2 \times 10^{16} \mathrm{~cm}^{-3}$ and $N_{\mathrm{A}}-$ $N_{\mathrm{D}}$ lies in the $10^{14} \mathrm{~cm}^{-3}$ range.

The moisture of the $\mathrm{B}_{2} \mathrm{O}_{3}$ encapsulant lowers the incorporation efficiency of the acceptor level (supposed to be carbon) [27] and the decrease of $C_{\text {As }}$ centres causes an increase of arsenic vacancies $V_{\mathrm{As}}$ and consequently reduces the $\mathrm{As}_{\mathrm{Ga}}$ centre related to the EL2 centre.

6.2 RAdial Distribution of EL2 CENTRE. - The quadratic symmetry observed in the upper part of ingots for electrical parameters can be related to the shape of the solid-liquid interface during the growth, the evolution of which depends on the convection patterns as the melt depth reduces. At the beginning 


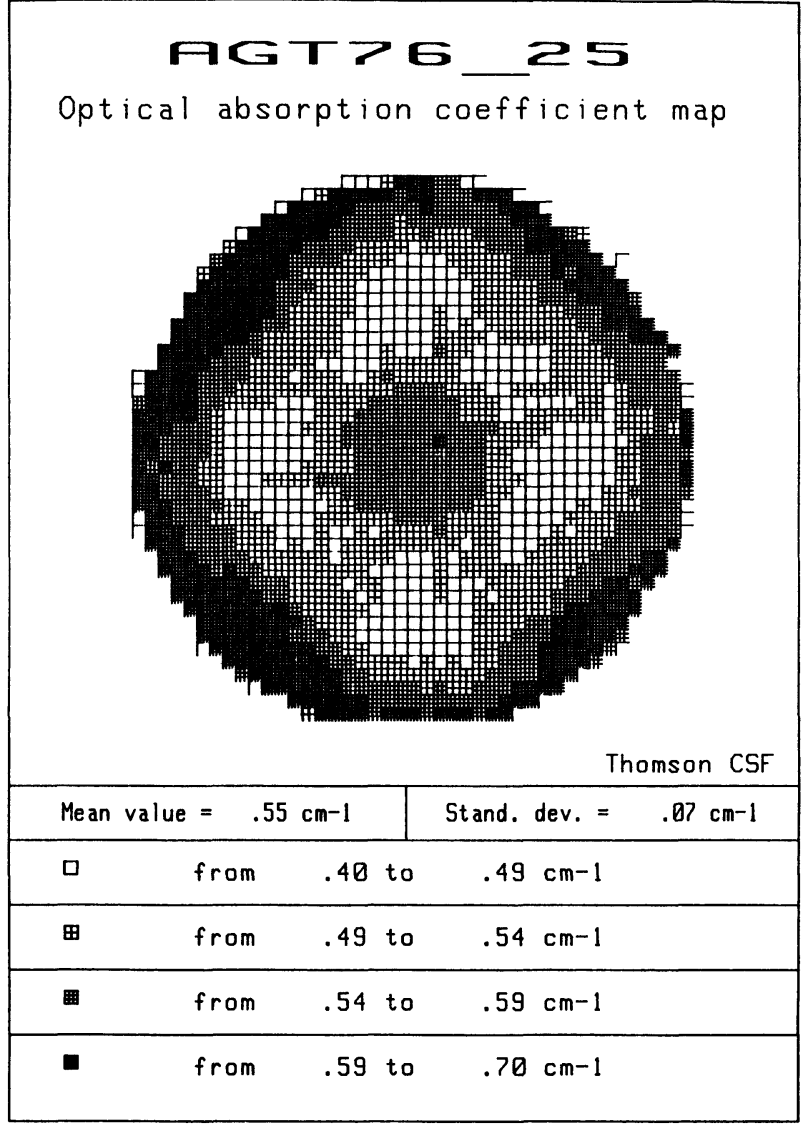

Fig. 7. - Optical absorption coefficient map at $300 \mathrm{~K}$ for a typical seed-end wafer.

of the growth the solidification surface may be submitted to some anisotropic growth rate and be at the origin of an anisotropic incorporation of impurities in the solid, due to segregation. When the melt level decreases in the crucible, the convection flow is strongly modified, stirring becomes more efficient and the solid-liquid interface shape is more dependent on the movement of the liquid. In this case, a core, corresponding to a local planar geometry of the interface, may appear at the centre and give the patterns observed for both the resistivity and the residual level.

The distribution of the EL2 centre on the wafer fits with the dislocations patterns observed in the upper part of the GaAs ingots. The EL2 concentration minima along the $\langle 110\rangle$ directions correspond with the dislocations concentration minima whose location was explained by Jordan [28] with a thermal stress field model.

In the lower part of the ingots (tail-end) the distribution of EL2 and of dislocations are not similar any more. The EL2 distribution patterns present an axial symmetry but the dislocation pattern still presents a four-fold symmetry as in the seed-end of the crystal. Then the mechanisms of formation for EL2 and the dislocations are neither similar nor do they involve the same parameters.

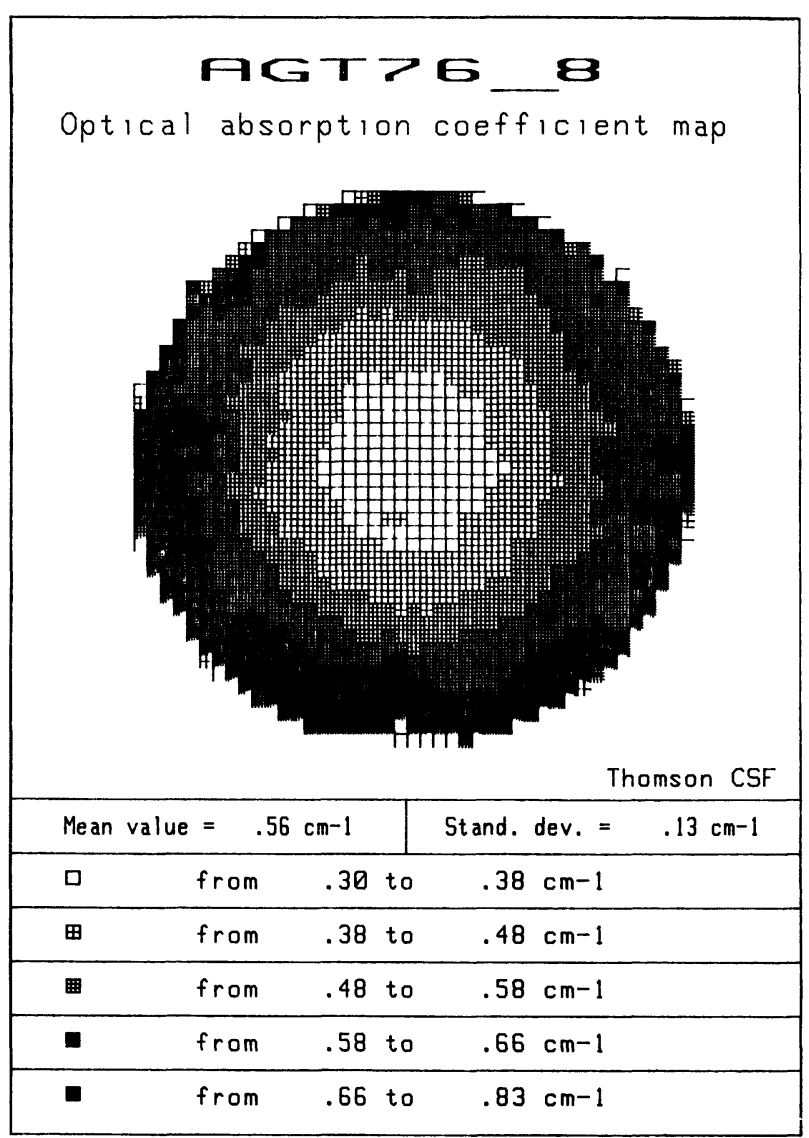

Fig. 8. - Optical absorption coefficient map at $300 \mathrm{~K}$ for a typical tail-end wafer.

The difference may be explained by the cooling down rate of the tail-end of the crystal. At the end of the growth the crystal is pulled up above the encapsulant and this process can stop the diffusion of $\mathrm{Ga}$ vacancies and then freeze out the EL2 distribution. In the upper part of the crystal the cooling rate is very slow, vacancies can diffuse in the thermal stress-field and then the distribution pattern of EL2 concentration can be close to the dislocation distribution.

\section{Conclusions.}

We used mapping characterizations based on Hall effect and optical absorption to measure the EL2 distribution in undoped semi-insulating GaAs. The results have shown :

- An influence of the moisture of the $\mathrm{B}_{2} \mathrm{O}_{3}$ encapsulant on the impurities incorporation and EL2 formation.

- A four-fold symmetry distribution of the resistivity, the free carrier concentration and the concentration of EL2 on wafers coming from the upper part of the crystals.

- A revolution symmetry for the resistivity, the free carrier concentration and the residual doping 


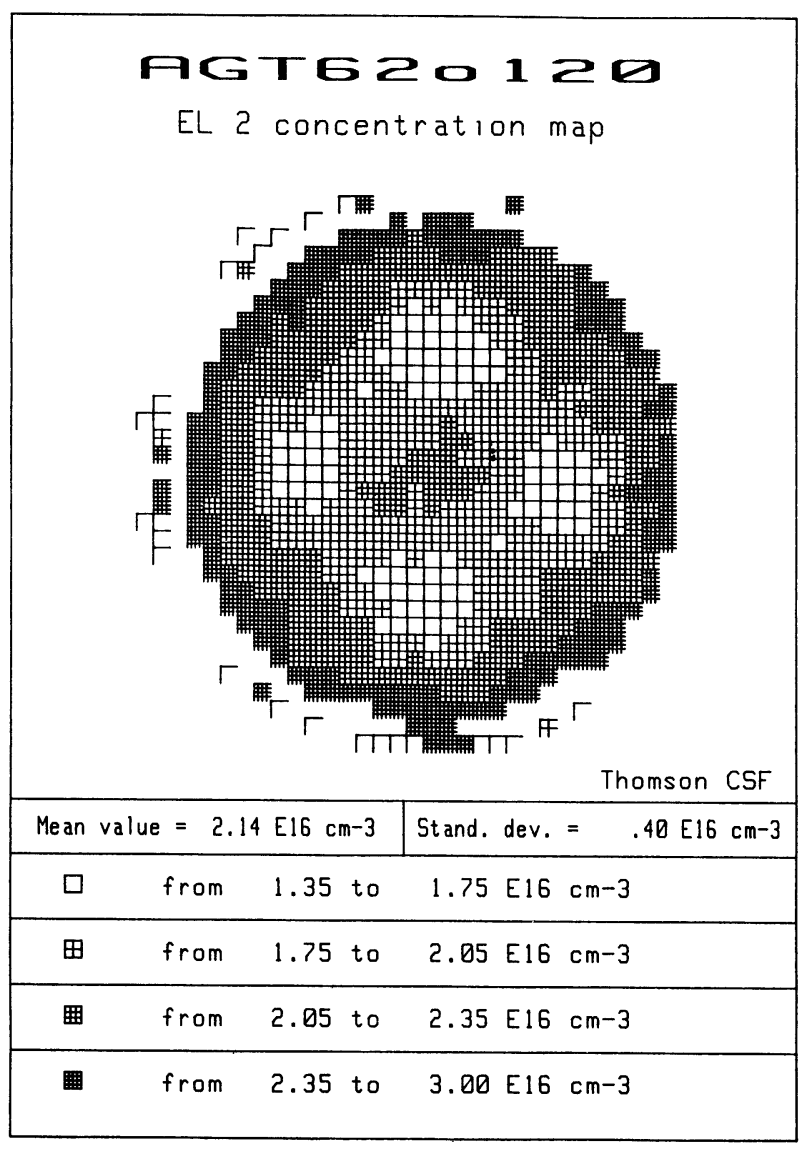

Fig. 9. - EL2 concentration map for a typical seed-end wafer.

level and almost no symmetry for EL2 concentration in wafers coming from the tail-end of ingots.

These behaviours can be explained in terms of growing and thermal conditions, two factors of prime importance for uniformity.

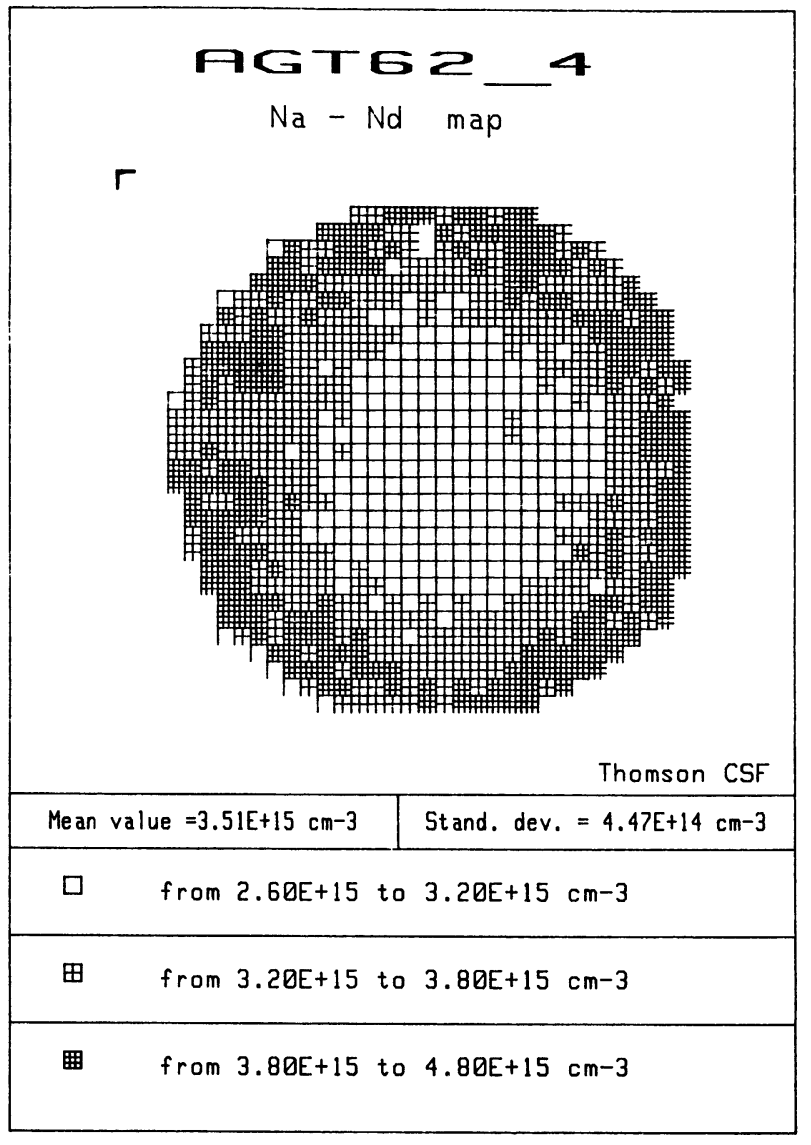

Fig. 10. - Residual doping level for a typical tail-end wafer.

\section{Acknowledgments.}

The authors wish to thank the French Ministry of Defence (DRET Department) for supporting this work and A. Lordereau for the preparation of the samples.

\section{References}

[1] Kitahara, K., Ozeki, M. and Shibatomi, A., Fujitsu Sci. Tech. J. 19 (1983) 279.

[2] Obokata, T., Matsumura, T., Terashima, K., Orito, F., KikUTA, T. and FuKUdA, T., Jpn. J. Appl. Phys. 23 (1984) L 602.

[3] Matsumura, T., ObOKata, T. and Fukuda, T., $J$. Appl. Phys. 57 (1985) 1182.

[4] Kamejima, T., Matsumoto, Y., Watanabe, $H$. and MAtsui, J., NEC Res. Dev. n 72 (1984).

[5] Bonnet, M., Proceedings of the International Symposium on Defect Recognition and Image Processing in III-V Compounds (DRIP) Montpellier (France) July 2-4 (1985), Mater. Sci. Monographs Elsevier 31 (1985) 105.

[6] Visentin, N., Bonnet, M., Gouteraux, B., Lent, B. and Lordereau, A., Rev. Tech. THOMSON-CSF 16 (1984) 261.
[7] Miyazawa, S., Ishit, Y., Ishida, S. and Nanishi, Y., Appl. Phys. Lett. 43 (1983) 853.

[8] IshiI, Y., MiYaZAwA, S. and IsHIDA, S., IEEE Trans. Electron. Devices ED 31 (1984) 800.

[9] Chen, R. T., Holmes, D. E. and Asbeck, P. M., Appl. Phys. Lett. 45 (1984) 459.

[10] Winston, H. V., Hunter, A. T., Olsen, H. M., Bryan, R. P. and Lee, R. E., Appl. Phys. Lett. 45 (1984) 447.

[11] Miyazawa, S. and Ishir, Y., IEEE Trans. Electron Devices ED-31 (1984) 1057.

[12] Matsuoka, Y., Ohwada, K. and Hirayama, M., IEEE Trans. Electron Devices ED-31 (1984) 1062.

[13] Visentin, N., Gouteraux, B., Bonnet, M. and LENT, B., Proceedings of the International Symposium on Defect Recognition and Image Pro- 
cessing in III-V Compounds (DRIP 1985) Montpellier (France) July 2-4 (1985), Mater. Sci. Monographs Elsevier 31 (1985) 117.

[14] Bonnet, M., Visentin, N., Lent, B. and RAFFet, C., Rev. Tech. THOMSON-CSF 15 (1983) 39.

[15] Winter, J. J., Leupold, H. A., Ross, R. L. and Ballato, A., J. Appl. Phys. 54 (1983) 5176.

[16] Gouteraux, B., Thesis, Université Pierre et Marie Curie (Paris 6) 1985.

[17] Mitonneau, A., Mircea, A., Martin, G. M. and Pons, D., Rev. Phys. Appl. 14 (1979) 853.

[18] Skolnick, M. S., Proceedings of the International Symposium on Defect Recognition and Image Processing in III-V Compounds (DRIP) Montpellier (France) July 2-4 (1985), Mater. Sci. Monographs Elsevier 31 (1985) 165.

[19] Holmes, D. E. and Chen, R. T., J. Appl. Phys. vol. 55, n 10 (1984) 3588.

[20] Dobrilla, P. and Blakemore, J. S., J. Appl. Phys. vol. 60, n 1 (1986) 169.
[21] Hasegawa, F., Iwata, N., Yamamoto, N. and Nannichi, Y., Jpn. J. Appl. Phys. Lett. vol. 22, $\mathrm{n}^{\circ} 8$ (1983) L 502.

[22] Lagowski, J., Lin, D. G., Aoyama, T. and Gatos, H. C., Appl. Phys. Lett. 44 (1984) 336.

[23] Iкома, T. and Mochizuki, Y., Jpn. J. Appl. Phys. Lett. 24 (1985) L 935.

[24] Chantre, A., Vincent, G. and Bois, D., Phys. Rev. $B$ vol. 23, n 10 (1981) 5335.

[25] Bonnet, M., Visentin, N., Gouteraux, B., Lent, B. and Duchemin, J. P., Proceedings of the GaAs IC Symposium, New-Orleans (USA) 1982.

[26] Fillard, J. P. and Castagne, M., MRS Symposium Proceedings 69 (1986) 231.

[27] Hunter, A. T., Kimura, H., Baukus, J. P., Winston, H. V. and Marsh, O. J., Appl. Phys. Lett. 44 (1984) 74.

[28] Jordan, A. S., Caruso, R. and Von Neida, A. R., Bell Syst. Tech. J. 59 (1980) 593. 